\title{
Study on Recycling Urban Wastewater for Non-Potable Uses for Water Conservation
}

\author{
Muthukrishna Vellaisamy Kumarasamy*, Victor N Dube \\ Civil Engineering Programme, School of Engineering, University of KwaZulu-Natal, \\ Durban, South Africa
}

Received: 28 June 2015

Accepted: 31 August 2015

\begin{abstract}
This study aims to investigate the feasibility of recycling urban wastewater for non-potable purposes and to reduce potable water usage in the eThekwini Municipal region in KwaZulu-Natal, South Africa. Three different potential users of recycled water were investigated, including residential households, industrial users, and irrigation schemes. For residential users, the water uses for low- and high-income households were investigated. For industrial use, one particular industry was investigated, and for irrigation schemes, three golf courses were investigated. Some of the factors were expected to affect feasibility, such as economic, social, and environmental issues. In this study economic and environmental feasibility were not considered as we were investigating water conservation. The study showed that industrial and irrigation uses are more feasible options for recycled water reuse as compared to residential use due to the low social acceptance of the project.
\end{abstract}

Keywords: recycled wastewater, daily water demand, non-potable uses, eThekwini Municipal Area, water conservation

\section{Introduction}

South Africa is a water-scarce country with high variability and unpredictability in its annual average rainfall of $450 \mathrm{~mm}$, compared to a world average of about $860 \mathrm{~mm}$ [1]. The country has very little water available, and what is available is limited by factors such as water pollution, climate change, and population. One of the ways to solve the water shortage issue and to reduce its anticipated effects is the development of an alternative water source for existing natural water sources. The eThekwini Municipality provides water and wastewater services in the Durban metropolitan area. In order to

\footnotetext{
*e-mail: kumarasamy@ukzn.ac.za
}

cope with the increase in water demand, it is proposed to investigate the feasibility of supplying recycled water for non-potable uses to the users. The non-potable uses do not need water to be treated to drinking water-quality standards, as this has proven to be unsustainable [2-3]. Wastewater reuse has an advantage of turning wastewater into a water source instead of a pollutant. For residential users, water can be supplied via a dual water supply system consisting of independent pipe networks supplying two grades of water. For industrial users and irrigation schemes, water can also be supplied in a separate network, but it may not necessarily run parallel to the potable water network. Water recycling in this context does not include reusing water that was used in carwashes, laundry, or bathing, which is referred to as grey water. The majority of water recycling has until recently been targeting large 
water uses like irrigation [4] and avoiding residential areas for reasons like costs and public acceptance, which may hinder their implementation [5]. This can also be seen in the case of Australia, where recycled water reuse has been implemented to a much smaller extent than proposed [4-6]. Treatment costs to achieve certain water-quality standards for residential reuse and the consequent pipe network requirements are very high [4].

In South Africa the use of recycled water via a dual supply network is not a common practice for domestic use. The eThekwini Region generates about 450 million litres/d of municipal wastewater from its 27 Wastewater treatment works (WWTWs). Currently only about $10 \%$ is being recycled (47.5 million litres/d) by treating to near-potable standards, and is being sold to two industries: Mondi Paper and the SAPREF refinery. None of the recycled water is being supplied to domestic users. However, this frees up sufficient drinking water for approximately 300,000 people [7].

This gives a clear indication as to how much potable water can be saved if water recycling is carried out more extensively. In terms of choosing the areas that can be supplied with recycled water, distance from the wastewater treatment works should be considered. This is primarily due to the cost of laying long-distance pipes and pumps for water distribution. Another factor is that the recycled water loses quality rapidly with increases in travel distance and time. Hence users located near the WWTW are usually the target market. The use of nonpotable recycled water in residential areas may pose a health threat if it is not up to a certain standard.

For farmers, the water requirements are sensitive to the nutrients that are found in wastewater. This may affect crop yield and also pose a risk of these being passed on to humans. Another disadvantage is that most farms are far from the WWTW.

The feasibility of water recycling projects is to be analyzed by considering expected savings, health, economic, and environmental issues. The savings that come from recycling water can be divided into two categories, such as financial savings to end users and freshwater savings. Industrial customers are used as examples to illustrate the expected financial savings. Firstly, Mondi Paper, the main client of the recycled water, saves up to $44 \%$ in water tariffs [7]. Similar savings are expected for residential users as reduced water tariffs could be an incentive to them to increase the acceptance of the project. In terms of potable water savings, the plant operating at full capacity can result in a savings of $7 \%$ of Durban's current potable water demand and reduce the amount of effluent being discharged into the environment by $10 \%$ [8]. If recycling is carried out at more WWTW, then similar savings are also expected.

It is the duty of the water authority to make sure that the recycled water is distributed in a regulated manner and does not result in illnesses or fatalities. This is seen in the Goreangab Water Reclamation Plant in Windhoek, Namibia, where no health issues have been recorded since the start of the water recycling project [9]. The success in Namibia shows that water recycling can be conducted successfully with no health issues. In Australia, cross connections between the potable and non-potable water pipes were avoided to eliminate the risk of drinking contaminated water to ensure the safety of human life [6].

Economic costs deal with costs to treat effluent, pipe network installation costs, and operation costs. It is important to design the system with appropriate pressure and flow velocities to maximize its performance [4]. Present values can be used in estimating the costs for a pipe network. But for operation and maintenance, present values that take into account a defined discount rate will have to be used to minimize life-cycle economic cost [4]. However, the actual costs calculations were not included in this study.

In terms of reliability, dual water systems are more reliable than single systems as it results in water shortages. This is because the non-potable water is a supplement for potable water, hence there will be fewer service interruptions compared to single systems. As we know, secondary wastewater treatment is the most energyconsuming process in the treatment of water. Since most WWTWs in South Africa are required to treat their wastewater up to secondary stage [7], adding a recycling plant would only result in a very small increase in energy use. It would also result in reduced energy demand in the potable water treatment procedures since this demand is expected to drop with the implementing of water recycling. However, this study only analyzes the data in a water conservation point of view and does not analyze the problem with energy and economic points of view.

\section{Materials and Methods}

Meter-reading records by the municipality were used to obtain an estimate of the water demand figures for residential households. Households were chosen from high- and low-income residential locations so as to represent extreme cases. A sample size was selected using statistical methods for each study area, and this was taken to represent the entire area. The suburbs of Westville and Waterloo were chosen to represent high- and low-income households, respectively.

The distribution proposed by Jacobs, et al. [10], was used to estimate the quantities for the various uses within a household. Data to be analyzed was chosen from urban formal areas without informal settlements to avoid inaccuracies. As each industry has its own demand, an estimate of the water demand for industries has to be carried out differently. Due to these reasons, the demand for each industry is to be analyzed independently and, unlike residential areas, the demand is not affected for the industry considered by climatic factors like rainfall and temperature.

This study analyzed the water demand of the Sappi SAICOR paper industry in Durban. The demand obtained was a total demand, as no information was obtained from Sappi about their potable and non-potable water demand. Data from the municipality was used to obtain 
an estimate of the water demand for golf courses. As there was insufficient data to separate between potable and nonpotable water demand of golf courses, the entire water demand was taken to be for irrigation. Hence that could be substituted by non-potable water. Three golf courses were chosen for the study and these are the Bluff, Royal Durban, and Kloof golf clubs.

To calculate the sample sizes for both areas, a confidence level of $95 \%$ was used in conjunction with a confidence interval of 5 . This was to allow for human error during meter reading since meters are read manually door-to-door and also for any other unforeseen errors. The following formula was used to obtain a sample size:

$$
\mathrm{n}=\mathrm{N} /\left[1+\mathrm{N} \alpha^{2}\right]
$$

$\ldots$ where $\mathrm{n}$ is sample size, $\mathrm{N}$ is the sample frame, and $\alpha$ is the margin of error.

\section{Results and Discussion}

Data for three different potential customers of recycled water were collected and analyzed as follows. The households were then chosen at random. The data obtained from the billing spread sheet was organized for calculating water demands. The non-potable demand was calculated for each household and the case for households with gardens was assumed as it would give the highest possible demand. The total number of households in Waterloo is 3,324 and corresponding sample size calculated is 357 . The total demand of water for the Waterloo area was about $0.31 \mathrm{kl} /$ day for each household as shown in Fig. 1. This value is slightly more than the free basic water (FBW) quantity supplied for free, which is $0.3 \mathrm{kl} /$ day. The nonpotable demand had an average of $0.26 \mathrm{kl} /$ day/household. This is the amount of potable water that can be saved by using recycled water and this is a significant amount, since it is about $80 \%$ of the total water demand.

\section{Water Demand for Residential Areas}

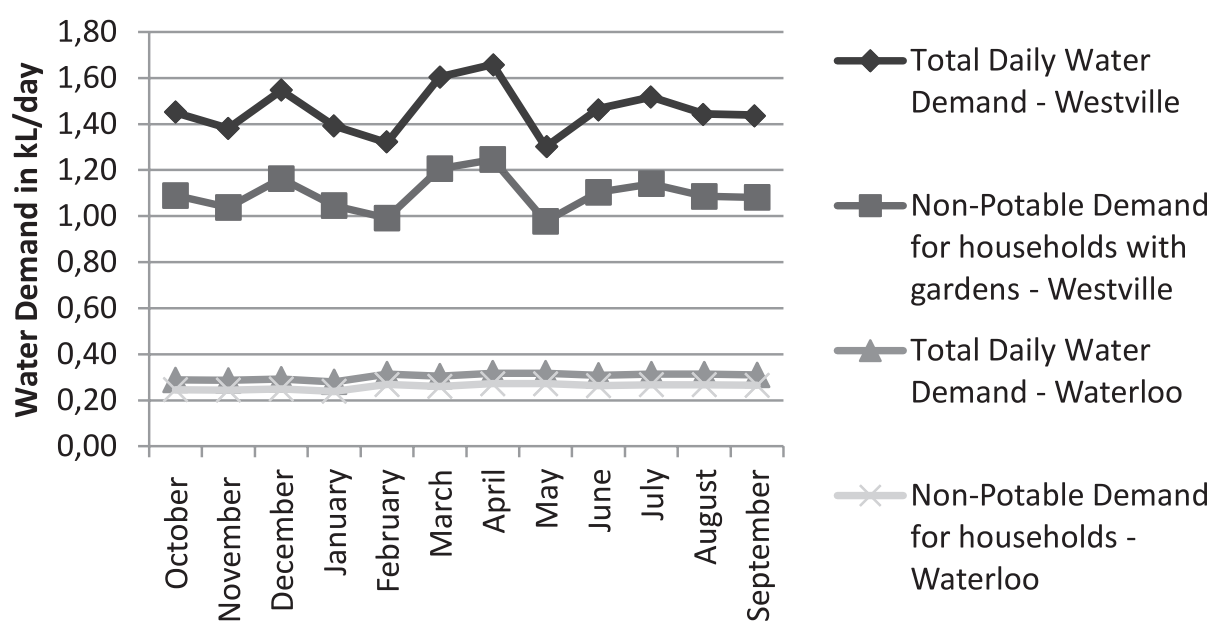

Fig. 1. Total water demand and non-potable water demand for residential areas [11].

Water Demand for Golf fields and an Industry
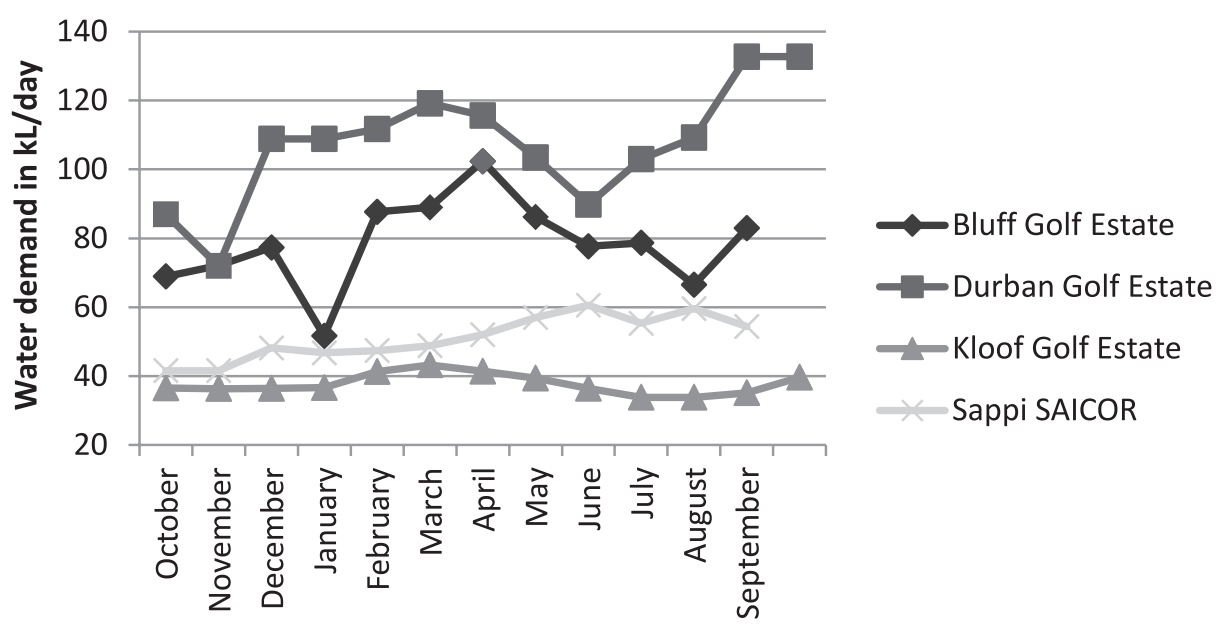

Fig. 2. Total water demands for golf courses and an industrial enterprise [11]. 


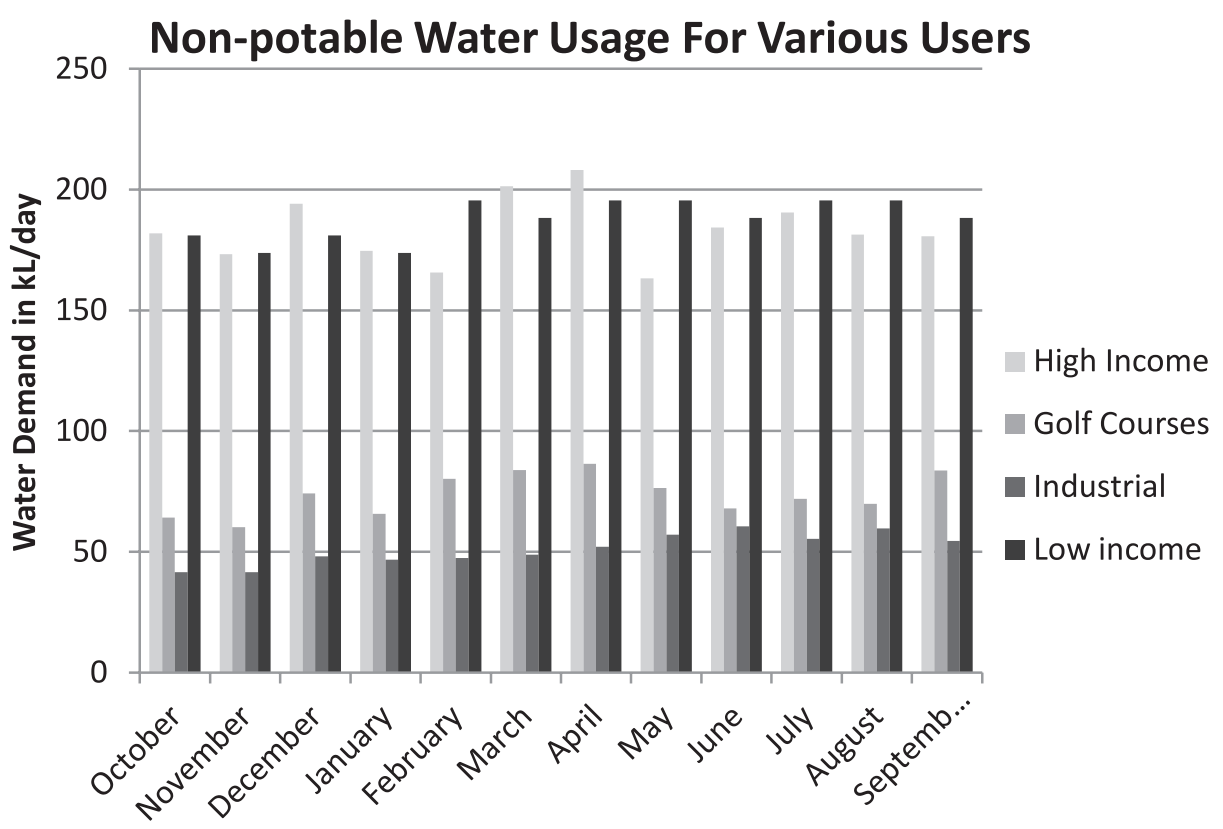

Fig. 3. Comparison of non-potable water demand for various users [11].

The disadvantage of using non-potable water in low-income households is that due to high household densities, the cost of installing a parallel network will be very high and since the daily demand of each household is approximately equal to the FBW, this means no income will be generated by implementing this scheme. In terms of saving potable water, the scheme is very feasible but financially it will not be feasible. The total number of households in Westville is 671 and corresponding sample size calculated is 251 . High income households have about three times the average water demand when compared to low income households as shown in Fig. 1.

Despite the significant increase in the amount of water used, these values are still relatively low for water recycling to be financially feasible when the costs for reticulation pipes and pumps are taken into account. However, if non-potable water were to be supplied, then high-income households would generate more revenue than the lowincome households. The industry of choice was the Sappi SAICOR Paper Industry, and since it was the only one in this category, there were no statistical methods applied to the data obtained. Fig. 2 shows that the water demand for the Sappi industry may have been increasing over the past year due to increasing production.

Fig. 2 also confirms that industrial processes are not affected by weather or climatic factors. The advantage of supplying the industrial areas is that there are no such reticulation costs involved, since only one large-diameter pipe can supply the whole site.

The data for three golf courses, namely Bluff, Kloof, and Durban, were first analyzed individually as shown in Fig. 2, and then an average value was obtained for comparison with other water users. Bluff has an area of $704,427 \mathrm{~m}^{2}$, which is the biggest of the three, yet its water demand lies in-between that of the other two courses. This shows that the water demand for a golf course may not necessarily increase at the same rate as its size.

The Royal Durban Golf Club has an area of $612,500 \mathrm{~m}^{2}$. It has the second largest irrigated area after Bluff, but the largest water consumption of all the golf courses - which is about double that of Kloof, which was found to have an area of 462,209 $\mathrm{m}^{2}$ and also requires the least amount of water among the clubs. It ranges with the industrial demand and these two also have the same advantage of not requiring complex reticulation pipes and pumps. However, this is only valid provided that they are located relatively close to the recycling plant. The graphs from nearly all the users (except industrial) have a similar trend, which shows that the demand for water peaks during winter (April-June) and is low during the rest of the year. This is likely due to the summer rainfall that occurs in Durban and is low or unavailable during the winter.

For the residential areas, the average demand was multiplied by the number of households located in a plan area equal to that of the average of the three golf course areas. The aim was to find how which of the users uses more water in a given area. The average area for the golf courses was calculated and it was found to be $539,045 \mathrm{~m}^{2}$. The average number of households located in a similar area was then calculated [11] at 167 high-income households and 724 low-income households. These values were then multiplied by the average demand for each household to get the total non-potable demands.

Fig. 3 shows that the highest water usage per $\mathrm{m}^{2}$ of land are the residential users. They are then followed by the industrial users, with the golf courses coming last. When the results are analyzed individually, it was seen that some golf courses use more water than industrial areas. This shows that when calculating the maximum demand that a particular WWTW can supply, individual water requirements for large water users like golf courses and industries should be used. Average values can only 
be used for residential areas where water requirements are more or less the same. Inasmuch as the total water demand for residential areas is more than that for the golf courses and even industry, the expense of setting up and maintaining reticulation networks for residential areas far exceed the other two users.

\section{Conclusion and Recommendations}

The study revealed that wastewater recycling is a feasible means of ensuring sustainable water use. The results obtained show that for all the users that were investigated, a minimum of $50 \%$ of their current water requirements can be met by substituting non-potable water for potable water. These values are higher for areas that are irrigated and some industrial users.

The comparison between users like residential households and golf courses was used for illustrative purposes. In reality, however, the water uses between these two cannot be compared directly since human consumption can be measured per capita, but that cannot be done for irrigation. However, for this study these results were compared and found that the water usage in residential households gives the highest water demand per given area. Unfortunately, water demand is not the only factor that is important in determining the feasibility of a water recycling project. There are other factors that influence wastewater reuse, such as social acceptance and cost of reticulation networks. These factors make residential use of recycled water the least favorable option among other users. Because all the water is sold to users, the scheme has a better chance of generating revenue as compared to residential use. So from a financial perspective, industrial and irrigational uses of recycled water give the most feasible options.

As reported by the Council for Scientific and Industrial Research (CSIR), about $62 \%$ of water in South Africa is used for irrigation-related uses, so it makes sense to propose water reuse for the largest water user in the country. In terms of capacity, no conclusion could be reached until a customer at a specified location with a known demand had been secured. The study shows positive results for water recycling and a large potential for potable water savings. For in-depth analysis, each user must be studied independently and consider all the factors affecting water reuse. This will give actual and unique quantities for each user instead of the average values that were provided in this study. Those results will be more accurate and can then be analyzed with the WWTW capacities to give more accurate estimations of how much potable water can be saved.

\section{Acknowledgements}

Authors acknowledge the Univerisity of KwaZuluNatal, South Africa, for supporting this study.

\section{References}

1. CSIR. A CSIR Perspective on water in South Africa. CSIR Report No. CSIR/NRE/PW/IR/2011/0012/A. 2010.

2. ILEMOBADE A.A., ADEWUMI J.R., VAN ZYL J.E. Framework for assessing the viability of implementing dual water reticulation systems in South Africa. Water SA. 35 (2), $216,2008$.

3. ADEWUMI J.R., ILEMOBADE A.A., VAN ZYL J.E. Treated wastewater reuse in South Africa: Overview, potential and challenges. Resources Conservation and Recycling. 55, 221, 2010.

4. KANG D., LANSEY K. Dual Water Distribution Network Design under Triple-Bottom-Line Objectives. Journal of Water Resources Planning and Management. 138 (2), 162, 2012.

5. WOODS G., KANG D., QUINTANAR D., CURLEY E., DAVIS S., LANSEY K., ARNOLD R. Centralized versus Decentralized Wastewater Reclamation in the Houghton Area of Tucson, Arizona. Journal of Water Resources Planning and Management. 139 (3), 313, 2013.

6. RADCLIFFE J. Evolution of water recycling in Australian cities since 2003. Water Science and Technology. 62 (4), 792, 2010.

7. ETHEKWINI MUNICIPALITY. EThekwini Draft Water Services Development Plan 2011. Durban, South Africa. 138, 2011.

8. PILLAY S. An environmental lifecycle assessment of the provision of recycled water in Durban. Ph.D. Thesis. University of KwaZulu-Natal, Durban. 237, 2007.

9. DU PISANI P.L. Direct reclamation of potable water at Windhoek's Goreangab reclamation plant. Desalination. 188, 79, 2006.

10. JACOBS H. E., GEUSTYN L.C., LOUBSER B.F., VAN DER MERWE B. Estimating residential water demand in Southern Africa. Journal of the South African Institution of Civil Engineers. 46 (4), 2, 2004.

11. N DUBE V. Investigating the feasibility of urban wastewater recycling for non-potable uses in the ethekwini region and the consequent savings in potable water, BSc (Eng) dissertation, University of KwaZulu-Natal, Durban, South Africa. 59, 2012. 
